\title{
Characterization of the purification and primary culture of adult canine myoblasts in vitro
}

\author{
WENHUI ZHU ${ }^{1,2}$, YUBIN WANG ${ }^{1,2}$, GUFENG QIU $^{4}$ and BINGGUAN CHEN ${ }^{3}$ \\ ${ }^{1}$ Nanjing Medical University, Nanjing, Jiangsu 210029; Departments of ${ }^{2}$ Sports Medicine, and \\ ${ }^{3}$ Central Laboratory, Shanghai East Hospital, Tongji University School of Medicine, Shanghai 200120; \\ ${ }^{4}$ Chinese Academy of Sciences, Shanghai Branch, Shanghai 200031, P.R. China
}

Received January 4, 2010; Accepted February 16, 2010

DOI: $10.3892 / \mathrm{mmr} 00000281$

\begin{abstract}
The aim of the present study was to explore a simple and efficient procedure to culture and purify adult canine myoblasts in vitro. Muscle from adult Beagle canines was isolated and harvested by mechanical decomposition and two-step enzyme digestion. The cells were then purified by a method involving differential adherent velocity and flow cytometry. The morphologic properties and growth states of the cells were observed, and the cell phenotype was characterized by flow cytometry, reverse transcription-polymerase chain reaction (RT-PCR) and immunocytochemistry. Approximately $98 \%$ of the adult canine muscle cells were positive for CD56 by flow cytometry. These cells expressed MyoD and myogenin as determined by RT-PCR, and desmin as determined by immunocytochemistry. Our method proved to be convenient and practical with a high probability of success. Studies of cell therapy using highly purified myoblasts may now be broadly applied to canine models of human muscle and non-muscle diseases.
\end{abstract}

\section{Introduction}

Myoblasts, situated beneath the basal lamina that surrounds each myofiber, persist in mature muscle as satellite cells, continue to fuse to adjacent myofibers during postnatal growth, and provide a source of cells for new muscle formation during muscle regeneration after injury (1). Native desmin-positive myoblasts, cultured as single cells, yield two major populations of myoblasts: $\alpha$-sarcomeric $(\alpha-\mathrm{SR})$ actin-positive myoblasts and desmin-positive myoblasts. In appropriate culture conditions, $\alpha$-SR actin-positive myoblasts

Correspondence to: Dr Yubin Wang, Department of Sports Medicine, Shanghai East Hospital, Tongji University School of Medicine, Shanghai 200120, P.R. China

E-mail: wenhuijj@sina.com.cn

Key words: Beagle canine, skeletal myoblast, culture in vitro, isolation and purification, cell therapy fuse into myotubes, whereas a population of desmin-positive non-fusing myoblasts (NFMBs) survive for weeks among the myotubes without fusion. These results suggest that muscle stem cells are present among NFMBs (2), and recent results have confirmed that human myoblasts contain muscle-derived stem cells (3).

The MyoD transcription factor plays a central role in the signaling pathways that regulate muscle development. The transfection and the subsequent forced expression of the MyoD gene in a variety of differentiated non-muscle cell types (fibroblasts, fat, melanoma, neuroblastoma, chondroblast, liver and retinal pigmented epithelial cell lines) may initiate the process of myogenesis (4). Myogenin, a member of the MRF family, also contains a myc-like region that is essential for myogenesis (5).

In 1990, Dr R.S. Walsh proposed that NCAM was a target cell surface antigen for the purification of muscle cells for myoblast transfer therapy (6). Since then, NCAM has been used for either the identification of myoblasts or the development of antibody-based purification techniques. NCAM cell surface expression can be identified by flow cytometric analysis with CD56 monoclonal antibodies. In vitro-propagated human myoblasts express the myoblast marker CD56 but not TE7, a marker associated with the muscle-derived fibroblast phenotype (7).

Myoblast grown in vitro may be used as a 'cell therapy' for hereditary muscle diseases (8). In addition to the treatment of intrinsic muscle diseases, the principles of myoblast transplantation have been extended to the treatment of hormone deficiencies (9), coagulation disorders such as hemophilia (10), stress urinary incontinence (11) and even neurodegenerative diseases (12). In addition, myoblast therapy has been applied to joint injury (13).

Many investigators have used pure myoblast populations from established cell lines for transplantation $(9,14)$. However, when transplanted into muscle in vivo, these cell lines have a propensity to form aberrant muscle fibers and even undifferentiated tumors (15). Primary cultures may overcome the limited host range of the currently available myogenic cell lines since they can be derived from any strain. Primary cultures may also avoid the problem of immunogenicity which is present with mixed primary cultures. Moreover, substrate- and often anchorage-independent growth, unlimited proliferation poten- 
tial and low requirements for serum and growth factors are all typical of cell lines and atypical of primary cells.

However, primary muscle cell preparations are often contaminated with a significant number of non-myogenic cells, such as muscle-derived fibroblasts. Most studies have used primary cultures from dissociated muscle, which are mixtures of myoblasts and non-myogenic cells that are mostly muscle-derived fibroblasts $(11,16)$. Under standard culture conditions, muscle-derived fibroblasts frequently overgrow the cultures, while myoblasts tend to differentiate and fuse into postmitotic, multinucleated myotubes. However, pure myoblasts are needed for use in cell therapies.

Although culture conditions have been established for the clonal growth of chicken, rat, human, mouse and fetal canine myoblasts (17-21), few previous reports have described detailed conditions for the successful cloning of highly purified primary adult canine myoblasts.

\section{Materials and methods}

Animals. Beagle canines, 1 year old, were obtained from the Agricultural Institute of Shanghai Jiaotong University, China. Animal care and experimental procedures were in accordance with the guidelines of the Administrative Panel on Laboratory Animal Care of China.

Preparation of primary cultures. Approximately $1 \mathrm{~g}$ of muscle from the hind limb of Beagle canines was dissected under sterile conditions. The muscle was minced into a coarse slurry using sterile surgical scissors and forceps. The muscle slurry was enzymatically dissociated by the addition of $0.25 \%$ trypsin-EDTA and $0.2 \mathrm{mg} / \mathrm{ml}$ type IV collagenase (class IV) (both from Gibco-BRL). The muscle slurry was then incubated overnight at $37^{\circ} \mathrm{C}$ in a humidified air atmosphere containing $5 \% \mathrm{CO}_{2}$. On the next day, the slurry was passed through an $80-\mu \mathrm{m}$ nylon mesh (Millipore Inc.). The filtrate was spun at $800 \mathrm{rpm}$ to sediment the dissociated cells, the pellet was resuspended in growth medium, and the suspension was plated in culture flasks.

Culture conditions. Growth medium for primary adult canine myoblasts consisted of Ham's F-10 nutrient mixture supplemented with 20\% FBS (both from Gibco-BRL) and $2.5 \mathrm{ng} /$ ml bFGF (Sigma, USA). Cell fusion into multinucleated and elongated myotubes was monitored by replacing the growth medium with differentiation medium. Differentiation medium consisted of DME (Gibco BRL) supplemented with 2\% horse serum (HyClone, USA). All media contained penicillin G (100 U/ml) and streptomycin $(100 \mu \mathrm{g} / \mathrm{ml})$. Cells were grown in plastic tissue culture flasks in a humidified incubator at $37^{\circ} \mathrm{C}$ in $5 \% \mathrm{CO}_{2}$. The growth medium was changed every 2 days, while the differentiation medium was changed daily. The morphology of isolated cells was visualized by phasecontrast light microscopy using an Olympus IX70 inverted microscope.

Cell purification by the differential adherent velocity method. Primary isolated cells from adult canine muscle tissue were first purified using a previously described technique (22). The cells were pre-plated in culture flasks and incubated in an incubator at $37^{\circ} \mathrm{C}$ in $5 \% \mathrm{CO}_{2}$ for $2 \mathrm{~h}$. The supernatant was then withdrawn from the flask and replated in a fresh flask. The cells that adhered rapidly during this 2-h incubation were mostly fibroblasts. Each time the cultured cells were passaged, the same process was repeated.

Cell purification and determination by flow cytometry. The percentages of $\mathrm{CD}^{2} 6^{+}$and $\mathrm{TE} 7^{+}$cells in the primary myoblast cultures were analyzed by Beckman Coulter flow cytometry. Since passage may have changed cell morphology, sorting by flow cytometric analysis was conducted prior to the first passage. Cultured cells were trypsinized, spun, washed in cold PBS containing $0.5 \%$ BSA (Roche, USA) and counted. The cells were then divided into equal aliquots $\left(\sim 5 \times 10^{7}\right.$ cells/ $\mathrm{ml})$ and spun to a pellet. FBS (4\%) in a PBS solution was used to resuspend each pellet, and the suspensions were incubated for $10 \mathrm{~min}$ on ice. For cell sorting, the primary antibody (mouse anti-canine CD56, 1:200 dilution in 3\% BSA/PBS; Santa Cruz, USA) was added directly to the tubes for $30 \mathrm{~min}$ at room temperature. The cells were then washed three times by centrifugation at $1,800 \mathrm{rpm}$ for $5 \mathrm{~min}$, and they were resuspended in ice cold PBS. The fluorochrome-labeled secondary antibody (goat anti-mouse, coupled to biotin and detected with streptavidin coupled to phycoerythrin) was added to the tubes containing the cells, and they were incubated for at least $20 \mathrm{~min}$ at $4^{\circ} \mathrm{C}$ in the dark. For cell determination, both the primary antibodies (mouse anti-canine CD56 and TE7 at a dilution of 1:200 in 3\% BSA/PBS) and the secondary antibody (CD56: anti-mouse monoclonal antibody coupled to biotin and detected with streptavidin coupled to phycoerythrin; TE7: anti-mouse monoclonal IgG coupled to FITC) were added to the same tubes. After centrifugation at $1,800 \mathrm{rpm}$ for $5 \mathrm{~min}$, the cells were ready for analysis by flow cytometry. Following sorting, the cells were plated on culture dishes for continued culture. The sorting by flow cytometry was applied once.

Assessment of growth indices of primary myoblasts. To assess the growth properties of purified adult canine myoblasts, the P4 (purified and passaged four times) cells were plated at a density of $1 \times 10^{4}$ cells $/ \mathrm{ml}$ in a 6 -well culture dish, and the number of cells in each dish was determined by hemacytometer counts after the cells were suspended by trypsinization every $24 \mathrm{~h}$. The population doubling times of the cells were determined during the periods when the cells were in logphase growth.

Reverse transcription-polymerase chain reaction (RT-PCR). Total RNA was extracted from the cultured myoblasts, muscle-derived fibroblasts and spermatogonia with TRIzoltrichloromethane reagent, precipitated with isopropanol and washed with ethanol. Total cellular RNA was used as a template for the synthesis of first-strand cDNA by reverse transcription (RT). A reaction mixture containing oligo (dT), $1 \mu \mathrm{g}$ of total cellular RNA and distilled water in a total volume of $7 \mu \mathrm{l}$ was heated at $70^{\circ} \mathrm{C}$ for $5 \mathrm{~min}$. Reverse transcriptase, RNAase inhibitor and dNTPs were then added to reach a total volume of $20 \mu \mathrm{l}$, and the mixture was incubated at $37^{\circ} \mathrm{C}$ for 2 h. Subsequently, the tubes were either stored at $-20^{\circ} \mathrm{C}$ or used immediately for PCR amplification. PCR amplification of first-strand cDNA was carried out using a final volume of $20 \mu \mathrm{l}$ 
comprising $10 \mathrm{mM}$ Tris-HCL (pH 8.3), $50 \mathrm{mM} \mathrm{KCl,} 1.5 \mathrm{mM}$ $\mathrm{MgCL}_{2}, 200 \mu \mathrm{M}$ of each of the $4 \mathrm{dNTPs}$ and 0.5 units of AmpliTaq (Takara, USA). The reaction mixture was preheated at $94^{\circ} \mathrm{C}$ for $3 \mathrm{~min}$ (hot start PCR), then cycled 20-40 times in a PCR thermal cycler (Minicycle ${ }^{\mathrm{TM}}$; MJ Research, USA). The primers and conditions were as follows: i) MyoD-denaturation for $30 \mathrm{sec}$ at $94^{\circ} \mathrm{C}$, annealing for $30 \mathrm{sec}$ at $58^{\circ} \mathrm{C}$, elongation for $50 \mathrm{sec}$ at $72^{\circ} \mathrm{C}$ and extension for $10 \mathrm{~min}$ at $72^{\circ} \mathrm{C}$ for 35 cycles yielded a PCR product of 972 bp. ii) Myogenin-denaturation for $30 \mathrm{sec}$ at $94^{\circ} \mathrm{C}$, annealing for $30 \mathrm{sec}$ at $57^{\circ} \mathrm{C}$, elongation for $50 \mathrm{sec}$ at $72^{\circ} \mathrm{C}$ and extension for $10 \mathrm{~min}$ at $72^{\circ} \mathrm{C}$ for 30 cycles yielded a PCR product of $552 \mathrm{bp}$. iii) Fibronectin-denaturation for $90 \mathrm{sec}$ at $94^{\circ} \mathrm{C}$, annealing for $60 \mathrm{sec}$ at $55^{\circ} \mathrm{C}$, elongation for $60 \mathrm{sec}$ at $72^{\circ} \mathrm{C}$ and extension for $7 \mathrm{~min}$ at $72^{\circ} \mathrm{C}$ for 32 cycles yielded a PCR product of $604 \mathrm{bp}$.

The following primers were used. MyoD: forward, 5'-CTG CCGGGATATGGAGCTGCT-3'; reverse, 5'-CCCTCAGAGC ACCTGGTAGATGG-3'. Myogenin: forward, 5'-GGCTGCT GGTCCCTCGCAG-3'; reverse, 5'-GCTCTGACCTCGGG CTTCG-3'. Fibronectin: forward, 5'-AGAGCATAGACACTC ACTTC-3'; reverse: 5'-CAGAAATGACTATTGAAGGC-3'. $\beta$-actin: forward, 5'-CCTCTATGCCAACACAGTGC-3'; reverse, 5'-GTACTCCTGCTTGCTGATCC-3'; PCR product size, 211 bp (23).

After PCR amplification, electrophoresis was performed using $10 \mu \mathrm{l}$ of the product in a $1.2 \%$ agarose gel containing $0.1 \mu \mathrm{g} / \mathrm{ml}$ ethidium bromide. The results were photographed with an ultraviolet transilluminator.

Immunocytochemistry for desmin staining. Cells were seeded in a 6-well culture dish for desmin staining. When the cells reached $30 \%$ confluence, they were fixed in $95 \%$ acetone in PBS for $30 \mathrm{~min}$ at room temperature. All further incubations were carried out at $37^{\circ} \mathrm{C}$. Triton X-100 (0.25\%), 5\% DMSO in PBS and $3 \% \mathrm{H}_{2} \mathrm{O}_{2}$ were used in turn. Goat serum (10\%) was used as a blocking solution for $30 \mathrm{~min}$. An antibody to desmin (mouse anti-canine monoclonal; Dako, USA) was applied at a dilution of 1:100 and incubated at $4^{\circ} \mathrm{C}$ overnight. After rinsing, an anti-mouse secondary antibody (1:200, DakoCytomation Envision $+{ }^{\circledR}$ System Labelled Polymer-HRP) was applied for $1 \mathrm{~h}$. The cells were rinsed with PBS and DAB H\&E was applied to stain individual nuclei.

\section{Results}

Cell culture characteristics. The adult canine muscle cells isolated from primary culture mostly contained muscle-derived fibroblasts that easily adhered and proliferated rapidly. Those cells were left behind and were gradually depleted from the culture using our differential adherent velocity method. Under the microscope, the muscle-derived fibroblasts appeared much more flattened (Fig. 1A), whereas the myoblasts were more compact and much smaller in diameter (Fig. 1B). The primary adult canine muscle cells became $80 \%$ confluent after 5 days of culture at a cell density of $5 \times 10^{7} / \mathrm{ml}$. When primary muscle cells became $80 \%$ confluent, they were passaged.

Before being sorted, the primary adult canine muscle cells contained both myoblasts $\left(\mathrm{CD}^{+} 6^{+}\right)$, fibroblasts $\left(\mathrm{TE} 7^{+}\right)$and other cells (CD56- and TE7-), as determined by flow cytometry (Fig. 1C)
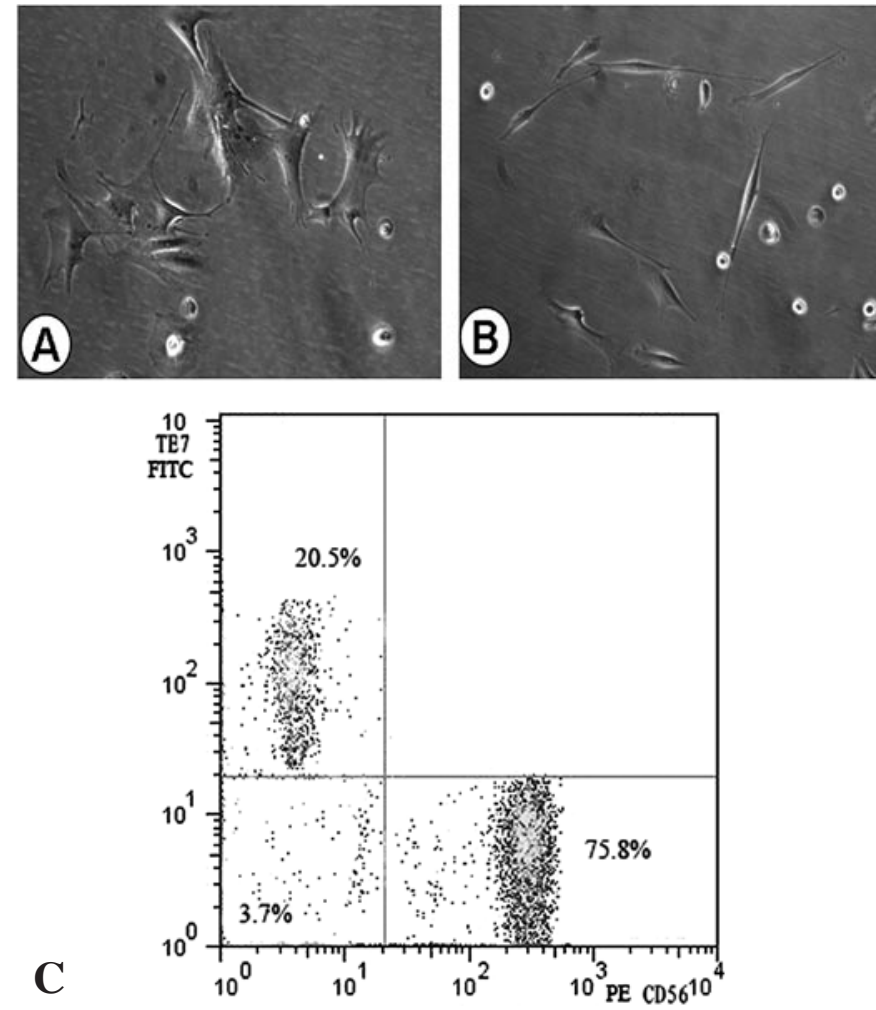

Figure 1. Different cell populations in primary adult canine skeletal muscle cells, as determined by morphology and flow cytometry. Muscle-derived fibroblasts appeared much more flattened (A), while myoblasts were spindlelike and much smaller in diameter (B) by morphology (x200). Myoblasts $\left(\mathrm{CD}^{+} 6^{+}\right)$, fibroblasts $\left(\mathrm{TE7}^{+}\right)$and other cells (CD56- and TE7-) existed in the primary adult canine muscle cells before being sorted by flow cytometry $(\mathrm{C})$.
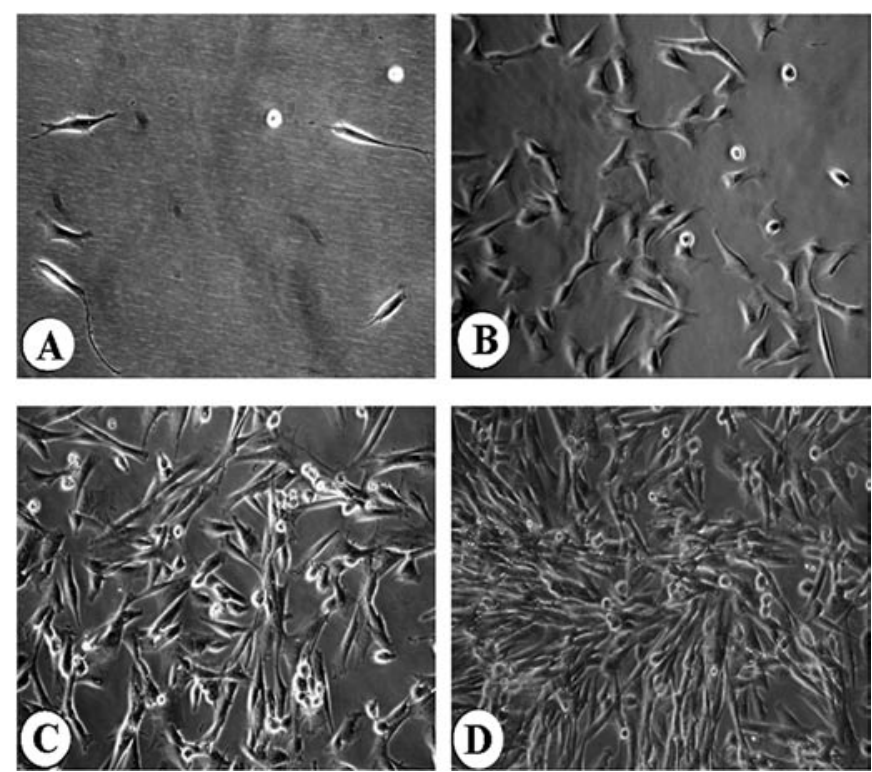

Figure 2. The morphology of $\mathrm{P} 4$ adult canine myoblasts at different times: $12 \mathrm{~h}$ after seeding (A), 3 days after seeding (B), 5 days after seeding (C) and 7 days after seeding (D) (x200).

For the P4 cells, cellular morphology was observed at different times. After being passaged, the P4 cells were plated in a 6-well culture dish at a cell density of $1 \times 10^{4} / \mathrm{ml}$. The P4 cells floated immediately after being plated and displayed a 
A

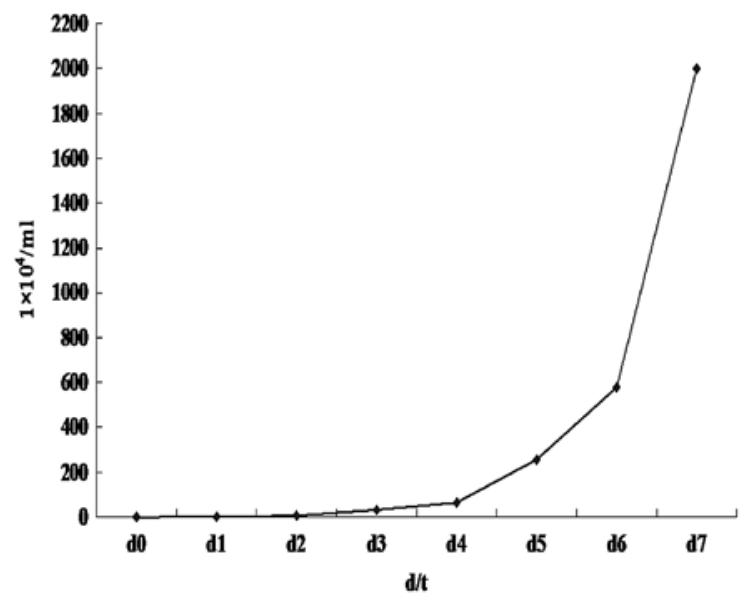

B

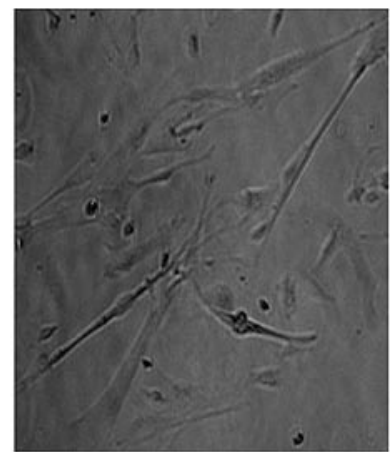

Figure 3. Growth curve of the $\mathrm{P} 4$ adult canine myoblasts cultured in vitro (A) Multinucleated, elongated myotubes fused by P4 adult canine muscle cells (B). rounded shape with high refraction. Twelve hours later, most of the cells adhered to the dish and had a small diameter, while there were still some non-adherent cells floating in the medium (Fig. 2A). On day 3, almost all of the cells adhered to the dish and appeared spindle-shaped (Fig. 2B). On day 5, the mononucleated cells became $60 \%$ confluent and had a characteristic elongated spindle shape (Fig. 2C). At this stage, most of these cells were in close contact with their neighbors. In addition, there were a few floating cells with low refraction, implying cell apoptosis. On day 7, the cell confluence reached $80 \%$, and the diameter of each cell became larger (Fig. 2D). At this time, the cells were passaged, otherwise they may have begun to differentiate into myotubes or die.

For the P4 cells, cellular proliferation was also assessed over time by manual cell counting. The results demonstrated a cell doubling time of $15 \pm 1 \mathrm{~h}$. By day 7 , the cell density reached $2 \times 10^{7} / \mathrm{ml}$ from the initial density of $1 \times 10^{4} / \mathrm{ml}$ (Fig. 3A).

When the adult canine P4 myoblasts were cultured with differentiation medium in 6-well culture dishes, the cells proliferated in large quantities, and large multinucleated myotubes were quite evident $\sim 48 \mathrm{~h}$ after medium replacement. By day 5, almost all myoblasts fused to form multinucleated, elongated myotubes (Fig. 3B).

Myoblast phenotypic characterization. Myoblast phenotypic characterization was performed by flow cytometry for CD56, RT-PCR for myogenin and MyoD and immunocytochemistry for desmin staining.

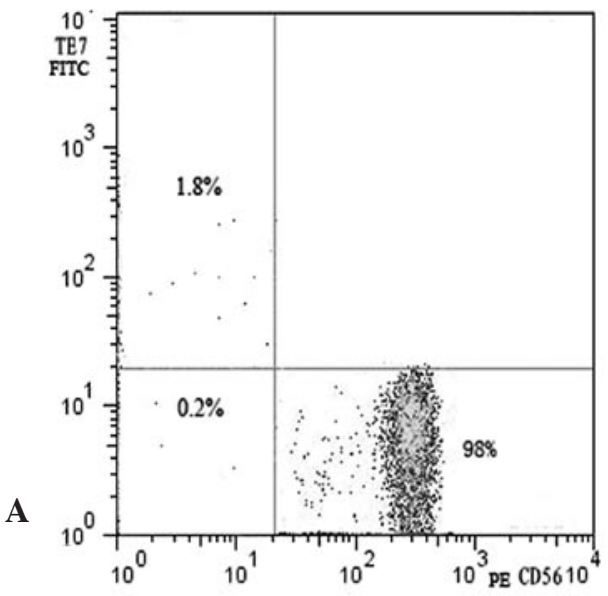

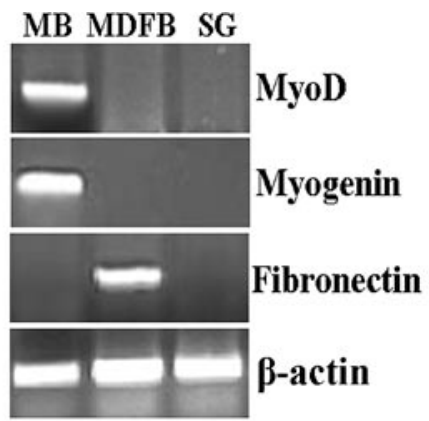

MB: myoblasts

B FB: muscle-derived fibroblasts

SG: spermatogonia

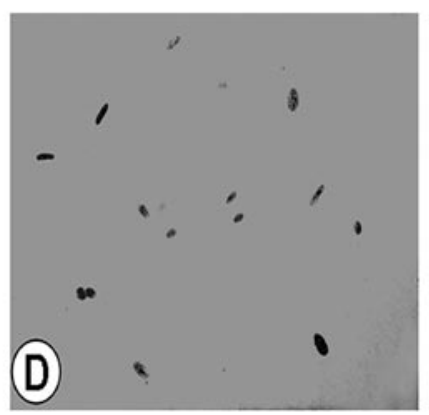

Figure 4. Characterization of the myoblast phenotype. Approximately 98\% of the P4 adult canine muscle cells were positive for CD56 (myoblasts) and negative for TE7 (fibroblasts) after being purified by flow cytometry (A). The MyoD and myogenin genes (the myogenic cell-related markers) were expressed only by P4 adult canine muscle cells, while fibronectin (the fibroblastic marker) was expressed only by the muscle-derived fibroblasts as determined by RT-PCR (B). The intermediate filament protein desmin (a myoblastic marker) was expressed by the P4 adult canine muscle cells as determined by immunocytochemistry staining $(\mathrm{C}, \mathrm{x} 100 ; \mathrm{D}, \mathrm{x} 200)$ 
Approximately $98 \%$ of the P4 adult canine muscle cells were positive for CD56 and negative for TE7 after being purified by our method (Fig. 4A). These results showed that highly purified primary adult canine myoblasts may be obtained by our method of purification.

RT-PCR analysis showed that the P4 adult canine muscle cells expressed the myogenic cell-related markers, $\mathrm{MyoD}$ and myogenin, instead of the fibroblastic marker, fibronectin. The muscle-derived fibroblasts expressed the fibroblastic marker, fibronectin, while they did not express myogenic cell-related markers, MyoD and myogenin. The spermatogonia did not express any of the above markers (Fig. 4B).

Immunocytochemistry staining showed that the $\mathrm{P} 4$ adult canine muscle cells were positive for the intermediate filament protein, desmin, which is a myoblastic marker (Fig. 4C and D).

\section{Discussion}

Myoblasts, which are adult stem cells and include skeletal muscle cell precursors, have been reported to possess multipotential mesenchymal stem cell activity and are capable of forming chondrocytes, osteocytes and adipocytes as well as myocytes $(24,25)$. These reports suggest that some degree of plasticity remains before terminal myoblastic differentiation. Therefore, myoblasts may potentially prove very useful for the development of new therapeutic approaches aimed at the regeneration of damaged or diseased tissues. Pure populations of primary myoblasts may be an excellent source for cell therapy as a) primary myoblasts have a remarkable proliferative capacity in vitro and fuse to host fibers; b) the hybrid fibers formed are stable in syngeneic hosts without immune suppression; and c) primary myoblasts appear to have no propensity to continue proliferating in an uncontrolled manner in vivo or to form tumors (20).

Rando et al demonstrated that myoblast-enriched cultures had a doubling time approximately $30 \%$ less (i.e., a higher growth rate) than that of fibroblast-enriched cultures when grown in F-10 (20). They also found that bFGF stimulated the growth of primary myoblasts to a greater extent than other growth factors, such as acidic FGF, platelet-derived growth factors $\mathrm{AA}$ and $\mathrm{BB}$, insulin-like growth factors I and II, epidermal growth factor and leukemia inhibitory factor; the maximal mitogenic effect of bFGF occurred at a concentration of $2.5 \mathrm{ng} / \mathrm{ml}$. In our study, F10 and bFGF (2.5 $\mathrm{ng} / \mathrm{ml}$ ) were also used for adult canine myoblast culture and proved to be efficient. Myoblasts were successfully obtained as indicated by the expression of the myogenin and MyoD genes and CD56. On the other hand, both the primary cells and the purified cells grew well without fusion into myotubes. In addition, the cells purified after four passages (P4 cells), which were almost all (98\%) myoblasts, reached a density of $2 \times 10^{7}$ cells $/ \mathrm{ml}$ on day 7 . This may enable the use of myoblasts in cell transplantation or therapy. When F-10 is replaced by differentiation medium, extensive differentiation of adult canine myoblasts occurs. This suggests that nutrient deprivation enhances myoblast fusion into myotubes. We also found that the purified adult canine myoblasts (at a cell density of $2 \times 10^{7} / \mathrm{ml}$ on day 7) appeared less proliferative than before purification (at a cell density of $5 \times 10^{7} / \mathrm{ml}$ on day 5 ). This may have been due to fewer cell types in the culture.
We sought to obtain pure populations of myoblasts from primary cultures of adult canine skeletal muscle that were mixtures of myoblasts and other cells, such as muscle-derived fibroblasts, hemocytes, endothelial cells and adipocytes. Most of the contaminating cells were muscle-derived fibroblasts. In our culture procedure, adult canine myoblasts were first isolated and harvested in vitro by mechanical decomposition and two-step enzyme digestion. The suspended hemocytes disappeared from the culture after several medium changes. Almost all endothelial cells, adipocytes and some musclederived fibroblasts were removed from the culture by our differential velocity adhesion method. However, some musclederived fibroblasts remained. To achieve highly purified myoblasts, we used flow cytometric sorting with CD56 monoclonal antibodies to remove the remaining muscle-derived fibroblasts. Using these procedures, we obtained highly purified myoblasts; approximately $98 \%$ of the cells were $\mathrm{CD} 56^{+}$at the 4 th passage.

In conclusion, myoblast therapy is currently in early phase clinical trials and has yielded positive results for many intractable clinical conditions, including muscleand non-muscle-related diseases. The establishment of the requirements for the superior growth of autologous highly purified primary myoblast cultures will facilitate myoblast transfer therapy. In our study, primary adult canine myoblasts were obtained by mechanical decomposition and two-step enzyme digestion. A nearly pure myoblast culture (approximately 98\%) was obtained by a combination of the differential adherent velocity method and flow cytometry. To summarize, our method of highly purifying primary adult canine myoblast cells proved to be convenient and practical with a high possibility of success. Our research has provided a foundation for the research of cell therapy with pure myoblasts from adult canine animals.

\section{Acknowledgements}

The spermatogonia were generously provided by Dr L.P. Zhang. We thank Professor G.D. Zhou for the critical discussion regarding the manuscript. This study was supported by the Shanghai Natural Science Foundation, China (No. 09ZR1425500).

\section{References}

1. Le Grand F and Rudnicki MA: Skeletal muscle satellite cells and adult myogenesis. Curr Opin Cell Biol 19: 628-633, 2007.

2. Baroffio A, Hamann M and Bernheim L: Identification of selfrenewing myoblasts in the progeny of single human muscle satellite cells. Differentiation 60: 47-57, 1996.

3. Alessandri G, Pagano S and Bez A: Isolation and culture of human muscle-derived stem cells able to differentiate into myogenic and neurogenic cell lineages. Lancet 364: 1872-1883, 2004.

4. Vilquin JT, Marolleau JP and Sacconi S: Normal growth and regenerating ability of myoblasts from unaffected muscles of facioscapulohumeral muscular dystrophy patients. Gene Ther 12: 1651-1662, 2005.

5. Puri PL and Sartorelli V: Regulation of muscle regulatory factors by DNA-binding, interacting proteins and post-transcriptional modifications (Review). J Cell Physiol 185: 155-173, 2000.

6. Walsh FS: N-CAM is a target cell surface antigen for the purification of muscle cells for myoblast transfer therapy. Adv Exp Med Biol 280: 41-46, 1990. 
7. Stewart JD, Masi TL and Cumming AE: Characterization of proliferating human skeletal muscle-derived cells in vitro: differential modulation of myoblast markers by TGF-beta2. J Cell Physiol 196: 70-78, 2003.

8. Gussoni E, Pavlath GK and Lanctot AM: Normal dystrophin transcripts detected in Duchenne muscular dystrophy patients after myoblast transplantation. Nature 356: 435-438, 1992.

9. Dhawan J, Pan LC and Pavlath GK: Systemic delivery of human growth hormone by injection of genetlcally engineered myoblasts. Science 254: 1509-1512, 1991

10. Dai Y, Roman M and Naviaux RK: Gene therapy via primary myoblasts: long-term expression of factor IX protein following transplantation in vivo. Proc Nat Acad Sci USA 89: 1089210895, 1992.

11. Chancellor MB, Yokoyama T and Tirney S: Preliminary results of myoblast injection into the urethra and bladder wall: a possible method for the treatment of stress urinary incontinence and impaired detrusor contractility. Neurourol Urodyn 19: 279-287, 2000.

12. Jiao S, Gurevich V and Wolff JA: Long-term correction of rat model of Parkinson's disease by gene therapy. Nature 362: 450-453, 1993

13. Day CS, Kasemkijwattana C and Menetrey J: Myoblast-mediated gene transfer to the joint. J Orthop Res 15: 894-903, 1997.

14. Yao SN and Kurachi K: Expression of human factor IX in mice after injection of genetically modified myoblasts. Proc Natl Acad Sci USA 89: 3357-3361, 1992.

15. Morgan JE, Moore SE and Welsh FS: Formation of skeletal muscle in vivo from the mouse C2 cell line. J Cell Sci 102 779-787, 1992.

16. Morgan JE, Hoffman Ep and Partridge TA: Normal myogenic cells from newborn mice restore normal histology to degenerating muscles of the mdx mouse. J Cell Biol 111: 2437-2449, 1990.
17. Konigsberg IR: Cellular differentiation in colonies derived from single cell platings of freshly isolated chick embryo muscle cells. Proc Natl Acad Sci USA 47: 1868-1872, 1961.

18. Richler $\mathrm{C}$ and Yaffe D: The in vitro cultivation and differentiation capacities of myogenic cell lines. Dev Biol 23: 1-22, 1970.

19. Blau HM and Webster C: Isolation and characterization of human muscle cells. Proc Natl Acad Sci USA 78: 5623-5627, 1981.

20. Rando TA and Blau HM: Primary mouse myoblast purification, characterization and transplantation for cell-mediated gene therapy. J Cell Biol 125: 1275-1287, 1994.

21. Li Y, Sagar MB and Wassler M: Apolipoprotein-J prevention of fetal cardiac myoblast apoptosis induced by ethanol. Biochem Biophys Res Commun 357: 157-161, 2007.

22. Petersen ZQ, Deasy B and Jankowski R: Identification of a novel population of muscle stem cells in mice potential for muscle regeneration. J Cell Biol 157: 851-864, 2002.

23. Zhu WH, Chen SY and Ren HM: Effects of Chinese medicine HuoXueShengJi on the mRNA expression of MHC-IIb, collagen-I and collagen-III in rat skeletal muscle after acute contusion of skeletal muscle. Chinese J Sports Med 23: 146-151, 2004.

24. Asakura A, Komaki M and Rudnicki M: Muscle satellite cells are multipotential stem cells that exhibit myogenic, osteogenic and adipogenic differentiation. Differentiation 68: 245-253, 2001.

25. Matsushita T, Matsui $\mathrm{N}$ and Fujioka H: Expression of transcription factor sox9 in rat L6 myoblastic cells. Connect Tissue Res 45: 164-173, 2004. 